\title{
Student Learning at the Interface of University and Industry Relating to Engineering Professionalism
}

\author{
Alison Joy Gwynne-Evans \\ University of Cape Town \\ Corresponding author: alison.gwynne-evans@uct.ac.za
}

(Submitted 13 September 2018; accepted 9 December 2018)

\begin{abstract}
The engineering profession is challenged with ensuring engineering students are prepared to work within industry in a professional and ethical manner. Reflection on the experience of professional practice is a key element in developing students' understanding of their professional and ethical roles. This paper builds on a theory of transformative learning based in the analysis of student assignments testing competence in one of the Engineering Council of South Africa's eleven exit level outcomes, that of Engineering Professionalism, within a fourth year capping course, at a South African university. It looks at final year students' responses to engaging with the professional environment in terms of their ability to demonstrate competence in engineering professionalism. This results in a nuanced analysis of student learning relating to the different forms of knowledge connected to professionalism and ethics and, thus, contributes to building new knowledge about student learning in the in the under-graduate engineering curriculum.
\end{abstract}

Keywords: engineering education, engineering ethics, professional practice, professional identity, student learning, transformative learning

\section{Introduction}

This paper seeks to link aspects of student learning to an analysis of the specific competence defined in terms of the exit level outcome of Engineering Professionalism. As such, the engineering students' assignments are accessed as evidence of student learning at the intersection of the university and industry in order to ascertain the extent to which competence in the particular exit level outcome can be successfully measured and achieved in an assignment of this sort. This research consequently examines and seeks to define the learning relating to professional knowledge and identity evidenced in the assignments. It builds on an understanding of learning as both acquisition of knowledge and the development of discursive identity (Allie et al., 2009: 362), where opportunities need to be identified for students to acquire and practice discourse relating to the development of an 
engineering identity, where professionalism is one facet of this identity. This analysis emerges from a three-year involvement teaching and critiquing final year students' engagement with ethics within a module, Professional Practice, that forms part of the fourthyear course of the Civil Engineering degree programme at the University of Cape Town. The research is grounded in a concern for how ethics can be effectively taught and learned within engineering courses with the aim of ensuring that graduating engineers are equipped to face the challenges of decision-making within the complex business environment in South Africa.

\section{Practical Context}

Within the under-graduate engineering degree at South African universities, students are assessed in terms of how competently they achieve the eleven exit level outcomes (ELOs), defined by the Engineering Council of South Africa (ECSA). Specific courses or modules within the engineering under-graduate degree are associated with different outcomes and specify the level at which the student is required to contribute to the particular outcome. The ELOs are defined to cover the range of competences ECSA requires in order that students are adequately prepared to start work in industry and to embark on their professional role as candidate engineers.

\section{Overview of Professional Practice Module}

The Professional Practice course is one of three capping courses within the Civil Engineering undergraduate programme that brings together a range of competences for assessment. Within this course, learning takes place through a combination of conventional lectures, the application and practice of skills, and experiential learning on a construction site. Students are allocated in teams to an engineering company contracted to a current engineering project and required to make contact and to set up a meeting with the different parties managing the project. They are required to visit the construction site and to engage with the project to identify different aspects of professional practice. This engagement between students and industry within the course occurs on several levels that include the students':

- experience of a professional environment through immersion in the day-to-day operations of a project,

- reflection on that experience with reference to the relevant exit level outcomes, as well as

- communication of the learning in a report and in an oral presentation.

The assessment of the Professional Practice course includes:

- Two tests covering subject matter that includes economics for engineers and the ability to demonstrate competent use of different analytical tools such as cost/benefit analysis or multi-criteria analysis. Each test counts $25 \%$ of the total course marks. 
- A group project report, counting $10 \%$ of the course marks, covering aspects relating to professional practice as demonstrated in the engagement with an operational construction site.

- Two essays, each counting $10 \%$ of the course mark, that require the students to inform themselves of the content of ELO 7 and 10 regarding the impact of engineering activity and their experience and understanding of engineering professionalism relating to their experience on the construction site.

- A group oral counting $20 \%$ of course marks covering selected areas of the project plan, showing the students' evaluation of their learning relating to professional practice.

In the specific assignment that forms the basis of the data of this research, students are required to demonstrate understanding of engineering professionalism (ELO 10). This relates to the students' understanding of their role as an engineer, beyond that of technical expertise. In addition, the outcome connects the student to their prospective professional responsibilities as defined in the ECSA Code of Conduct which outlines professional conduct for qualified engineers. The specific requirements include a 300 -word essay focused on 'describing engineering professionalism in the area reported on by the student in the Construction Project Report', and which requires the student to demonstrate, to the satisfaction of the external examiner, 'his/her appreciation for engineering professionalism in typical situations' (CIV 4041F Course Outline 2017 on Vula).

\section{Transformative learning as part of the development of professional identity}

Learning as the acquisition of knowledge and skills can be seen as formative (Biggs, 2002). Learning becomes transformative (Lillis, Harris, Lea \& Mitchell, 2015) where it affects the identity of the learner. In this final year course, students engage in a focused manner with concepts relating to their identity and understanding of themselves as professionals. Knowledge is presented as an entity to be integrated, used, and created, where student engagement with knowledge is consequently experienced as active, productive, and transformative. Knowledge here is seen as powerful (Young, 2009) because of its ability to affect how people position themselves within a context. Knowledge is, thus, recognised to be situated (Rose, 1997), where what is known affects the knower's vision and capabilities and their sense of identity and agency in the world. Learning consequently gives impetus and context to action and in turn forms and transforms knowledge and how that knowledge is used. In her work concerning student learning, Mitchell characterises transformation 'not...as a finished state, something that is fully achieved, (but) rather ...(as) an inclination towards envisaging alternative understandings of, and actions within any particular context' (cited in Lillis et al., 2015: 15). Transformative learning is seen to require transformative practices involving 
shifts in a number of human spheres: thinking, feelings and actions. These shifts require changes in how we have learned to think of, feel about and act upon the world around us, including ourselves, the relations of power underlying institutional structures, opportunities for access to knowledge and resources, as well as opportunities for success. (Gimenez \& Thomas, 2015: 30)

Transformative practices, thus, recognise that knowledge in all its forms - technical, practical, propositional, and procedural - is central to transformation and that learners can become more visible participants of academic practices through inquiry, critical thinking, and dialoguing with peers and lecturers (Gimenez \& Thomas, 2015:30). Student learning can be recognised to shape and be shaped by student experience and engagement with knowledge in specific ways. Learning within a particular context, therefore, needs to be documented and interrogated in order to understand what is learned and how that learning might be demonstrated or assessed. Trowler and Trowler (2010) highlight the need to develop a robust body of evidence built up through small-scale studies that seek to 'confirm, challenge or redefine' other studies, so that, rather than stand-alone evidence, 'a more integrated picture can emerge of practice and effect'. In a similar vein, in their synthesis of the literature on student engagement, Wimpenny and Saven-Baden (2013) recommend further studies engaging with students' understanding of 'their' learning.

In the South African context, positioning learning as transformative opens possibilities for engagement, innovation and change that are not possible where learning is seen primarily as formative or as a commodity. Winberg (2018) highlights the need for more South African studies into the transformative potential of the STEM (science, technology, engineering and mathematics) disciplines. In this context, a situated analysis of a particular engagement by students with learning relating to ethics in engineering provides an opportunity to explore and define more clearly aspects of student learning relating to the process. Sehakian and Seyfang (2018: 238) delineate transformative learning to empower students to challenge existing beliefs and practices, and to take action on the basis of their analysis. This formulation links transformative learning to the learning outcomes of engineering professionalism in that professionalism requires recognition of the "need to act professionally and ethically and to exercise judgement' (Sehakian \& Seyfang, 2018: 238) where this requires critical engagement with practice as well as the preparedness to act.

This research on engineering students' learning in relationship to their professional responsibilities builds on research into student learning regarding identity within the engineering field (Allie et al., 2009; Case, 2007), skills development (Nudelman, 2015), and the specifics of cognitive learning (Wolmarans, 2010; Young, 2008). The paper explores what is specific to learning concerning engineering students' knowledge of professional responsibility and the students' expanding conception of how that affects their professional identity. This recognises transformative learning as a desirable objective of the engagement of students with professional responsibility. Learning is seen as potentially connected to 
knowledge acquisition, participation in identity formation, and the creation of meaning (Sfard, 1998).

Professionalism may be positioned as a 'threshold concept' (Meyer \& Land, 2005) that needs to be encountered in order to transition into a new mode of understanding. Meyer and Land (2005: 374) argue that 'as students acquire threshold concepts and extend their use of language in relation to these concepts, there occurs ... a shift in the learner's subjectivity, a repositioning of the self'. This would appear to be evidence of the transformative effect of learning that needs to be anticipated and nurtured into fullness. Students encounter the construction site as a professional space and are required to reflect on that experience from the perspective of the particular learning outcome relating to engineering professionalism. This encounter is overtly structured by the Engineering Council of South Africa's policy of assessing student competence in terms of exit level outcomes (ECSA, 2014).

This analysis contributes to the debate exploring the readiness of engineering students to participate effectively in industry (Martin et al., 2005; Jawitz et al., 2005). By focusing on student responses to this engagement with industry, as demonstrated in their assignments, the paper contributes to building new knowledge about student learning regarding engineering professionalism and ethics in their under-graduate degree.

Professionalism and ethics are areas of learning that are recognised as important for aspirant engineering professionals to engage with (van der Vorst, 1998). However, precisely what is involved in this learning is not always clearly identified. There are approaches that emphasise compliance with codes of conduct (Davis, 1991) and other approaches that emphasise the need to develop judgment (Connolly, Arkes \& Hammond, 2000). This research seeks to establish a view on what is learned based in an understanding of learning as transformative in a manner that complements other approaches in engineering education

Internationally, the initiative known as Conceive-Design-Implement-Operate (CDIO) has proved to be a productive way to examine the engineering education curriculum from a process perspective. This ties engineering education to engineering process in a valuable way. Curriculum reform initiatives within engineering education in South Africa have incorporated these principles (Woollacott, 2009). The strength of the CDIO approach is its focus on integrating design and process in the wider curriculum. This provides the opportunity to look at specific curriculum initiatives concerning the role of the engineer as a professional in South Africa. Woollacott's rubric shows a correlation between his taxonomy and the wider engineering syllabus (2009: 552, Table 3). He defines four main categories of competence, namely technical knowledge; personal and professional skills and attributes; interpersonal skills; and conceiving, and designing, implementing, and operating engineering systems. What is interesting is that ethical considerations are not clearly evident in these categories or the associated second level categories. This provides an opportunity to engage with engineering professionalism in such a way to enhance understanding of ethical considerations. Whereas there has been research detailing student response in interviews to the challenge of engaging with industry in their work experience, this study looks at student responses to engaging with the professional environment, relating to a particular 
construction site, in terms of their ability to demonstrate their competence in a specific ELO, that of engineering professionalism.

\section{Methodology}

This research falls within the category of social science research on engineering students' practice in that it engages with qualitative data and interpretive method in order to bring new understanding and insight into existence with the goal of enhancing both the understanding of the learning process of engineering undergraduate students and the understanding of professional engineering responsibility. It is not a neutral descriptive process but an intentionally transformative process. It extends Sayer's (2011) insight that what we do in research, as in other areas of life, has value and inherently matters. This effectively connects the descriptive intent of social science with normative and philosophical concerns in a way that recognises that the research focus on specific issues within a discipline or practice is inherently affected by the understanding of what is important and meaningful. This is influenced, but not determined by, experience and context.

Sahakian and Seyfang's (2018) study used a methodology that linked the identification of competencies to transformative learning. In the same way, this study seeks to build from a close analysis of the learning required in the achievement of competencies to an understanding of the potential for transformative learning. The research looks at student learning as exemplified in student assignments that demonstrate critical reflection on experience. It focuses on analysing what is learned in terms of how knowledge is defined and understood. This interrogation of the actual artefacts of learning submitted as student assignments complements the undertaking of professional bodies to ensure learning outcomes are clearly defined, and in turn feeds into future revisions of these outcomes in a positive and iterative process (compare ECSA 2004 with 2014).

The focus of much qualitative research regarding student learning has shifted from what is learned to how students learn. This shift supplements an acquisitive model of learning with a participative model (Allie et al., 2009: 360) and affects, and is affected by, the conception of what constitutes knowledge (Krathwohl, 2002: 217). Because knowledge is seen as constructed within communities of practice, research builds on an expanded understanding of "learning" to include content, skills, attitudes, and discourse, where learning is seen to be acquired both in theory and through practice. The consequence of this is that learning is seen to include both:

- $\quad$ Overt student learning regarding professional practice as intentionally demonstrated by students in their essays, and

- Covert learning concerning power relationships and priorities that is acquired by means of the students' involvement with professionals and the construction site. This may be implicitly, rather than explicitly, evident. 
Qualitative studies are seen to offer a valuable means of examining student engagement due to the more personalised perspectives and illuminative experiences that qualitative studies provide, which are often difficult to locate through analysis of national student survey data, typically reported upon within quantitative studies' (Wimpenny \& SavenBaden, 2013). Wimpenny and Saven-Baden (2013) recognise that the phase of data interpretation requires a process of critical thinking and inductive analysis. In this context, it is useful to identify this interpretative role as potentially transformative.

This study builds on insights developed in reviewing teaching and learning relating to ethics and professionalism within the Professional Communication Studies curriculum at the University of Cape Town (Gwynne-Evans \& English, 2014) and seeks to clarify what would constitute evidence of different aspects of learning relating to ethics and professionalism. It engages from a teaching practitioners' perspective with ECSA documents $(2004 ; 2014)$ detailing assessment criteria and a range of outcomes for ELO 10. It must be noted that current versions of the document (ECSA PE-02, 2014) do not attempt the same level of detail of description of criteria as the earlier version (2004). The 2004 version was used in the early analysis of this research data and is seen to be more helpful in defining distinct levels of knowledge and associated criteria.

While Woollacotts' (2009) taxonomy of competencies and quality assurance provides a detailed and thorough analysis relating to engineering process, this research provides a small-scale analysis of assessment of a particular ECSA ELO relating to professionalism. This research uses qualitative data obtained through accessing fourth year Civil Engineering student assignments and offers an interpretation of the data in terms of the objectives and assumptions of the research. The analysis relates to the responses of the 2017 cohort of students as recorded in their assignments submitted in partial fulfilment of the Professional Practice course on Vula, the University's online learning management system. There were approximately 92 students registered for the course, reflecting a diversity as regards gender and race with most students falling in the age range 20-25 years.

The study does not attempt to formulate general trends or tendencies of student responses but looks instead at specific instances of student learning that demonstrate aspects of the learning outcomes. This study intends to build a more nuanced understanding of what competence in a specific learning outcome entails. This analysis thus feeds into the evaluation of the assessment process in a way that enables a more focused interrogation of the adequacy of formulation of the learning outcomes and their criteria for assessment.

The student assignments require students to reflect on their experience of professional practice within an operational construction site and to thus develop their understanding of professional responsibility in terms of ECSA's ELO 10 (ECSA 2014). Key concepts implicit in ELO 10 are identified and made explicit. The assessment criteria within the ELO are examined in order to identify and make explicit the different levels of knowledge they engage with. Student essays are analysed using qualitative discourse analysis to see how they have addressed these concepts and criteria. 
Student learning is seen to be both the focus and the context of the research, and thus learning is open to be changed by the process of reflection (Lillis et al., 2015: 41). This view is inherently different to one which considers the process of researching learning as an objective and neutral reflection of a static reality. The analysis will aim to interrogate various questions:

- What learning?

- Learning by whom?

- Learning for what purpose?

From this critical engagement, strategic initiatives are identified that can enhance the transformative effect of the engagement between industry and the profession.

This research engages at an initial level with a specific exit learning outcome of the Engineering Council of South Africa (ECSA) and the criteria used to define it. Further, it engages with ECSA policy relating to professionalism for engineers, exemplified in the Code of Conduct (ECSA, 2017). This engagement conceptualises knowledge in several ways both as content (knowledge of something) and as skill (how to do something). Engagement with these two levels of knowledge requires a response at a third level, which recognises the impetus of beliefs and values and positions the learner in relationship to those beliefs and values. This requires a different sort of knowledge, that is, knowledge of the self and professional identity in relation to these values and beliefs. At a metacognitive level, there is a further level of knowledge involving the ability to use concepts and to reason with those concepts in a critical engagement with beliefs and values. These dimensions of knowledge can be related to Krathwohl's (2002: 217) four dimensions of knowledge that include factual, procedural, conceptual and metacognitive.

It is evident that an engagement with learning that starts with the identification of knowledge of the content of policy documents and professional requirements quickly translates into engaging with the skills required for evaluation of concepts and identities in a way that is intentionally interpretative and transformative, both of practice and of that identity. Competence in a learning outcome requires engagement with the different levels of learning taking place relative to the different forms of knowledge that have been identified. This qualitative critical analysis of student responses captured in their assignments thus enables the process of learning by drawing attention to the process of learning and identity formation that occurs within a particular discourse and through the means of that discourse. It aims to distinguish and make explicit different types of knowledge assumed as relevant and the varied levels of learning demonstrated within student assignments.

\section{Assumptions}

The paper assumes that the process of engaging critically with both engineering policy and practice is potentially productive and beneficial. In this way there is both an analytical purpose, as well as a transformative intent. Furthermore, it models an understanding of the 
potential of the university to play a transformative role within and in collaboration with industry. The interface of the university and industry that is represented in the students' essays is assumed to be that which is experienced by the students and is consequently examined as a particular example of learning-in-practice. This research assumes the agency of the active learner in a particular context and consciously extends the boundaries of the learning experience to include the students' engagement with their professional identity through engagement with the professional space beyond the university.

\section{Analysis of the criteria of assessment for ELO 10}

In the Professional Practice course, students need to demonstrate they have achieved a competent level in ELO 10. This is defined by the Engineering Council of South Africa (ECSA) as being able to 'demonstrate critical awareness of the need to act professionally and ethically and to exercise judgment and take responsibility within own limits of competence' (ECSA, 2014). In the course, the student is specifically instructed to '[d]iscuss how engineering professionalism and ethics are/not being evidenced (as applicable) in the construction project investigated' (CIV 4041F Course notes, 2017). In supplementary correspondence with the students (CIV 4041F, Announcement on Vula 27 th June 2017), the students are directed to:

- Define how you are using the word professionalism and/or ethics (a reference may be useful)

- Describe what you saw on site

- Relate what you saw on-site to your definition, showing your ability to interpret and evaluate what you saw.

Here the exercise of engaging with an engineering team on-site as a case study requires the student to develop the ability to demonstrate critical awareness of the need to:

- act professionally;

- act ethically;

- exercise judgement; and

- take responsibility within limits of own competence.

As the student is not yet a professional engineer, they are not yet required to take on the actual responsibilities of the professional engineer but need to demonstrate their critical awareness of these aspects. The associated assessment criteria (ECSA, 2004) for engineering students, defined by ECSA in ELO10 as Engineering Professionalism, relate to the ECSA Code of Conduct (2017), and include the following:

- Being aware of requirements to maintain continued competence and to keep abreast of up-to date tools and techniques; 
- Displays understanding of the system of professional development.

- Accepts responsibility for own actions;

- Displays judgment in decision-making during problem-solving and design;

- Limits decision-making to area of current competence;

- Reason about and make judgment on ethical aspects in case study context; and

- Discerns boundaries of competence in problem solving and design (ECSA, 2004).

These criteria can be grouped in four distinct areas of student learning relating to engineering professionalism as defined in the exit level outcome. The first group of criteria requires the student to demonstrate objective knowledge of external issues, such as being aware of requirements and keeping up-to-date with technological tools and techniques.

A second group of criteria are those that require the student to reason about and make judgment on ethical aspects in case study context. This reflection requires the student to apply their skill objectively to reason in a situation in which they are not personally involved. This will involve theoretical and academic knowledge and the application of skills identifying issues and building a logical argument. It does not require the inclusion of values or beliefs or emotions.

The third group of criteria requires the student to demonstrate personal engagement with issues, such as those involved in accepting responsibility for own actions and displaying judgment in decision-making during problem-solving and design, as well as limiting decisionmaking to areas of current competence, and discerning boundaries of competence in problem-solving and design. The criteria in the third group require a different sort of knowledge and response, namely, knowledge about yourself and your abilities and a commitment to making ethical decisions that might have personal and professional cost. The responses to this group of assessment criteria cannot be learned academically but need to be learned in practice as the student responds to challenges in lived experience.

On a fourth and meta-level, the responses also require and even assume a level of conceptual understanding about what ethical choice involves, what counts as a decision, how decisions are made, and what alternative ethical choices are available. It is significant that conceptual understanding is assumed both in the ECSA ELOs and in the ECSA Code of Conduct where there is no explicit attempt to engage with the meaning of words like "'ethics', 'competence' or 'integrity'.

These four categories of assessment criteria form the structure supporting what needs to be assessed in order to reliably assert that a student has obtained ELO10. The assessment task needs to demonstrate a variety of levels of knowledge:

- objective knowledge of systems and procedures and content;

- $\quad$ knowledge demonstrating skill, such as how to build an argument;

- $\quad$ self-understanding and an engagement with personal values and choices; and

- conceptual knowledge and engagement with the way one concept relates to another. 
In order for the student to demonstrate that they have achieved competence in the specific ELO through the experience of engaging with professionals on the construction site, the student needs to engage with the criteria of assessment of ELO10 and to show understanding of the need to act professionally and ethically, to exercise judgement and to take responsibility within the range of competence. The students' reflection needs to start with an objective account of what was observed on-site. It then needs to proceed to demonstrate how the student grappled with the conceptual knowledge required in the situation. It moves through the process of exercising judgement on an external issue through to the engagement with personal meaning-making. This process effectively enables a transformative engagement where both the student and the context of learning (the construction site) are potentially changed by the interaction.

\section{Analysis of levels of student learning in response to Exit Level Outcome 10}

The following analysis takes examples of student learning relating to the four areas of professionalism identified above and examines how particular student responses illustrate engagement with the four levels of knowledge. It is important to note that examples cited are selected as illustrative of the distinct level of knowledge rather than being selected as defining a particular criterion. In this way, there may be alternative extracts from other students' work that could equally well make a similar point.

The first example demonstrates how the student engages with an issue using three different levels of knowledge. Initially, the student demonstrates knowledge of the specific context:

An example of this would be that the tender document stipulated $X$ man hours should be met. The contractor supposedly would not be able to meet this requirement. He/she was trying to negotiate with the client that if he/she used more BEE companies, would he/she be able to bypass these missed man hours.

Here the student attempts to represent the situation in an objective manner using descriptive language. The student continues and applies reasoning and judgment to the situation:

The contractor should strive to meet the man hours and if at the end of the project these man hours were not met then he/she should pay the penalty for this.

Here the student makes an objective judgement on a situation external to themselves. The student can be seen to respond to the requirement that they demonstrate the ability to 'reason about and make judgement on ethical aspects in a case study context' (ECSA, 2017). They are not required to come up with a correct judgement. 
On a third level, the student demonstrates personal engagement with what they have encountered when they formulate a judgment on an issue:

I felt this to be ethically incorrect.

This formulation shows a level of personal knowledge and commitment to the ethical decision-making process that, although perhaps simplistic, nevertheless brings the learning experience into the sphere of personal meaning-making. It is within this context that the student can exercise a developing sense of professional identity and commit to a particular version of ethical obligation.

Another way of operating in this personal knowledge sphere would include formulations, such as the following where the student went beyond the requirements of the assignment to reflect on the impact of the engagement with the project on his/her own sense of what it is to be a professional engineer:

This project has taught me to look deeper into the way professionals present themselves and given me an understanding of how I should behave when I enter the profession.

The two formulations above involving personal engagement show a distinct difference in their understanding of the scope of their responsibility. In the first, the student responded as a professional engineer making a judgement on an external situation as a participant and/or stakeholder; in the second, the student shows a clear and sustained attempt to engage in meaning-making. Both these examples also engage differently with meaningmaking. In the first, there is awareness of learning by association through exploration and engagement with a case study. It also involves modelling professional decision-making within a context where there is limited responsibility. In the second, there is reflection on the learning that has occurred relative to the student themselves and to their developing sense of their professional identity.

The following section demonstrates variations in student expressions of their learning as related to the application of conceptual knowledge in ELO10. Students use the terms 'professionalism' and 'ethics' in a variety of ways with very different effects.

Students may choose to use an existing definition of professionalism, such as in this example where the student defines professionalism as:

the way in which engineers conduct themselves in their work as well as in society (IEEE, 2012, as quoted by a student).

Standing on its own, this definition is rather bland and restricts the understanding of professionalism to conduct. It can, however, be seen as useful in that it provides a springboard for further engagement with the concept rather than being an exhaustive 
definition. This example demonstrates the need for the student to engage with how they use definitions of concepts, where an existing definition may limit further exploration of a concept or, alternatively, to stimulate further critical engagement with the definition, contextualising it in terms of the experience on-site.

The extract below shows the student exploring the boundaries and relationships of the two concepts 'professionalism' and 'ethics:

Professionalism refers to behaviour that adheres to specific standards within a professional field. In terms of engineering this refers to the adherence to defined standards with regards to communication etiquette, time management and delivery of designs and products of an acceptable quality. Professionalism also requires ethics. Ethical behaviour involves integrity as its fundamental principle with further issues like accountability, equity and consistency with how one makes decisions.

This student has differentiated between professionalism as conduct adhering to certain standards and behaviour, which is seen to be principle-based.

Another student demonstrated awareness of the complexity of demands on the engineer and an awareness of the obligation of professional responsibility even in the face of challenges to personal interest:

Engineers are required to display this trait [professionalism] in all their work particularly when considering the potential effects of their projects on the physical, social and economic environment within which they are working. This means that in situations where an engineer knows that the impact of their activity may be adverse, they must immediately cease the activity and reconsider their method of implementation or even the entire activity. This reconsideration must be done regardless of potential monetary losses and even at the expense of their own material wealth and reputation.

It is evident that the student extends the sphere of professional responsibility to counter personal interest and to establish normative principles.

Several students associate professionalism and ethics with an obligation to consider the interests of the wider society. One example is profiled below:

Engineering professionalism involves ethics and a responsibility to use the training received as an engineer for the benefit of the greater good of the public and not for self-gain.

This shows a clear conception of the professional having an obligation to the public beyond their own interests. The following extract builds on this conception showing clear reasoning and the application of this wider definition of professionalism: 
The contractor also employed workers from neighbouring disadvantaged communities. This decision was both ethical and professional. This showed that an engineer's professionalism doesn't only stop at the design or construction phase but includes the consequences of the engineering project on the lives of the community he aims at helping.

Here the engineers' responsibility is understood as larger than process-related issues and to continue into the future beyond the design or implementation stage. These are not specifically engineering issues but relate to consequences of engineering decisions on the social (or natural) environment.

Students show their valuing of the need to shift from a professional culture that is compliance-based to an actively ethical culture:

However, while the concepts and guidelines of professionalism are well established for most engineering projects, they have no meaning unless acted upon by those in the industry. This calls for the conscious practice of these guidelines.

This can be seen as both a personal challenge to be taken up and as motivation moving the student, as aspirant professional, towards a transformative agenda.

Students demonstrate their ability to exercise judgement and to identify (un)ethical behaviour in different ways. In the first example an infringement is contextualised in terms of the relevant code of conduct:

Client displayed biased behaviour when they had decided to only employ labourers from a specific ward. This was viewed as unfair as it prevented the other wards from obtaining employment. This resulted in protest action from locals. According to the ECSA's Code of Conduct (2017), any form of employment should be fair, unbiased and lead to no possible conflict of interest.

This shows the students' ability to motivate for specific action in terms of their understanding of specific aspects of the particular professional code.

Students show their awareness of the practical challenges to implementation and the consequences of unethical decisions for long-term self-interest. In the next example, the student applies their new knowledge concerning ethical behaviour to the context of the construction site and shows the ability to reason about and make judgments on ethical aspects in context:

In order to deliver the product up, the tendering process was run twice before construction activity could begin. This was ... due to the first contractor having defaulted on a project some time back. However [despite]... the bidding price of the contractor having rendered him the winner, his lack of integrity in past projects 
deprived him the opportunity to be selected for the project. This encounter reinforces the importance of loyalty and integrity in the engineering industry. That is to say it is essential to comply by the standards of quality work over ... compromised work quality.

Students also picked up on the difference between compliance as a tick-box exercise in order to escape prosecution versus applying compliance in the interests of the public:

At the client's request, there was no requirement in the tender documentation for the use of emerging contractors or local labour. Although the Consultant negotiated with the contractor to maximise the use of local labour where possible after the tender had been granted, it is my analysis that this was not professional nor ethical.

Here the student recognised the need for clear parameters in the tender documents as well as open communication between the different parties and the need for transparency between parties.

Students showed understanding of the obligation to ensure the professional execution of a job even where it went beyond the requirements of the contract:

The contract did not stipulate that the clearing of culverts needed to be done. However, the contractors did so out of concern for potential flood hazards. This was an example of the contractor acting by their ethical obligation to the profession to safeguard the environment and protect life.

The student recognises the practical obligation to do more than is required by law. The following example shows the desirability of affirming the requirements of ethical responsibility over mere compliance with the letter of the law, with potential serious consequences for public safety. The student writes:

The consultant claimed that their responsibility would be to only erect signs, which state 'no pedestrian access' and they, thereafter, could not be held liable for any accidents. This although technically deemed acceptable by the safety officer, is an unethical situation as no actions are in fact being taken in order to actually prevent pedestrian access to the site.

Such formulations are significant in that they contribute to a discourse of professionals as ethical and being obligated to serve public rather than the commercial interest.

The extract below shows an objective response to a situation where a worker died: 
When the accident occurred and resulted in the death of the worker, the construction manager was cleared of any charges. All regulations were met, and the traffic accommodation plan was strictly followed.

This response is inadequate precisely because it stays at the level of description and does not attempt to engage with exercising judgement or meaning-making in a situation where a person had lost their life. As aspiring professionals, it is in complex situations like this that students will need to develop the skill and confidence to exercise judgment and to identify key issues. As such, this response does not clearly demonstrate competence in engineering professionalism but stays at the level of describing the situation. Instead of demonstrating learning relating to exercising judgement in professionalism, the student instead demonstrates learning relating to knowledge of procedures and requirements. It is important that opportunities to assess both aspects of professionalism are identified.

Students show growing confidence in their ability to make judgements that impact the status quo. Here a student exercises their own transformative power when they demonstrate agency in relation to a situation in which conflicting cultural norms are experienced. The student assertively puts forward a new position justifying an alternative norm of conduct that could expand the conception of what it is to be professional:

According to the stipulated rules, the majority of the personnel on site were not permitted to communicate with visitors unless prior permission was given. This rule, however, was at odds with African social convention which dictates that whenever contact is made between 2 individuals, the younger of these individuals must respectfully greet the other, and a minor degree of small talk is expected.... While this convention is at odds with the stipulated rule, its purpose is to reinforce social cohesion.

This contribution is particularly interesting in the way it affirms the students' role and preparedness to actively engage with and transform the system. The student presents a case for a shift of convention and the incorporation of different practices to affirm the values of a different stakeholder group. This contribution raises important questions as regards who is represented by prevailing standards and conventions. Affirming and incorporating contributions from a diverse range of engineers/stakeholders could be very significant in ensuring professional standards and codes are representative of the values of stakeholders.

\section{Conclusions}

These examples demonstrate the diversity of student responses, the different levels of learning that may be evidenced and the student's growing ability to appreciate ethical challenges in different situations. Furthermore, the analysis recognises the value of providing the opportunity for students to formulate judgements relating to the case study in question. 
Because of the professional requirement for engineers to act with integrity and responsibility, it is essential that assessment requires the student to engage with their personal value system and to develop the skills to relate these values to the choices they will be faced with and the decisions that will need to be made. This is summed up by a student in the following extract:

This project has taught me to look deeper into the way professionals present themselves and given me an understanding of how I should behave when I enter the profession.

Learning needs to be conceptualised as differentiated and to be scaffolded on the different criteria of the specific exit level outcome, where the requirements of the assignment need to be specified relative to what is required of the student. The workplace experience of the student on the engineering site is key to providing a context where the student can grapple with practical challenges in the light of their new and established values, and their increased level of knowledge and skills. This gives the student the opportunity to prepare themselves for the professional environment where they will be required to use professional judgement to make decisions. This further requires the student to transfer general objective principles about case studies to a personal frame of reference and presents the opportunity to transform conceptual knowledge and skill into the level of personal knowledge and meaning-making.

This analysis clearly shows the importance of critical engagement with learning at the interface of the university and industry. It also demonstrates the importance of engagement with the artefacts of that learning in a way that recognises different types of learning that can be exhibited and provides a platform for insights and innovation to be channelled back into industry. It is evident that students draw on different sorts of knowledge in their engagement with what they have learned in relation to the workplace. The different formulations are useful steps in developing an understanding of what professionalism and ethics entails.

The analysis portrays students as able to contribute actively to the professional ethos rather than portraying them as passive receivers of an already established culture and ethos. It shows the role of research in promoting the agency and critical awareness of both teaching staff and students involved in a course and confirms the potential transformative impact of research on the participants: from the students and researcher to the institution and even industry.

\section{Implications of the research}

This analysis has implications for curriculum and course designers in that it suggests the assessment of competence within a qualification can be better nuanced and scaffolded to define the specific sorts of student learning that are possible and that need to be assessed. It further demonstrates the value of requiring sustained engagement with the teaching and learning process relating specifically to professionalism and ethics and challenges the role 
and responsibility of the course convener and/or lecturers in facilitating the students' shift from neutral observer to active upholder of behaviour that is ethical and professional.

This research affirms the value of a partnership with industry for the development of aspirant professional identity in students in order to develop knowledge, judgement and critical skills relating to professional identity in a way that would otherwise be difficult to replicate. It supports the active development of opportunities for the university to connect with constituencies such as professional bodies and industry in a manner which builds in opportunity for mutual learning. It also recognises the need to ensure a respectful culture of engagement and to model professional and constructive collaboration at all levels. The analysis supports a wider generative engagement with professionalism and ethics in collaboration with professional bodies such as the Engineering Council of South Africa.

\section{Acknowledgements}

I would like to thank the students from CIV 4041F, in particular the 2017 cohort, for their engagement with ethics and professionalism both in the class discussions and in their groups' reflection on their experiences on site, as well as in their ELO essays, and for granting me permission to access and quote from their essays in this research.

Also, a huge thank you to Professor Marianne Vanderschuren for her encouragement and guidance in the sharing of her scholarship and practice.

\section{Author Biography}

Alison Joy Gwynne-Evans teaches professional communication and ethics part-time within the Faculty of Engineering and the Built Environment at the University of Cape Town where she has been employed for ten years as a contract lecturer and facilitator. Gwynne-Evans' interest in how ethics is taught to engineering students is grounded in her post-grad studies in philosophy and has been fuelled by media stories highlighting the need for ethics and professional judgement in companies' decision-making. She is intent on ensuring students are equipped to engage with the challenges they will face in their professional lives and in industry. To this end, she embarked on an unfunded $\mathrm{PhD}$ in engineering ethics.

\section{References}

Allie, S., Armien, M.N., Burgoyne, N., Case, J.M., Collier-Reed, B.I., Craig, T., Deacon, A., Fraser, D.M., Geyer, Z., Jacobs, C., Jawitz, J., Kloot, B., Kotta, L., Langdon, G., Le Roux, K., Marshall, D., Mogashana, D., Shaw, C., Sheridan, G. \& Wolmarans, N. 2009. Learning as acquiring a discursive identity through participation in a community: Improving student learning in engineering education, European Journal of Engineering Education, 34 (4): 359-367.

Beder, S. 1998. The new engineer: Management and professional responsibility in a changing world. South Yarra, Australia: MacMillan Education.

Biggs, J. 2002. Aligning the curriculum to promote good learning, Constructive Alignment in Action: Imaginative Curriculum Symposium. 
CIV 4041F Course notes, Construction Project, 2017, Accessed from University of Cape Town Vula site. https://vula.uct.ac.za/access/content/attachment/1976932b-49524b6a-9e1f-e4382a09476d/Announcements/f04292e0-46f1-437f-b8d26c9867fbcca3/CIV4041F\%20Construction\%20Project\%20instructions\%202017.pdf [Accessed: 5 April 2018]

Connolly, T., Arkes, H. \& Hammond, K. (Eds.). 2000. Judgement and decision-making: An interdisciplinary reader (2 ${ }^{\text {nd }}$ edition). Cambridge: Cambridge University Press.

Davis, M. 1991. Thinking like an engineer: The place of a code of ethics in the practice of a profession. Philosophy and Public Affairs, 20 (2): 150-167.

Engineering Council of South Africa (ECSA). 2004. Whole Qualification Standard for $\mathrm{BSc}($ Eng)/B Eng NQF Level 7. PE-61 Revision 2. 26 July. https://docplayer.net/6045358-Engineering-council-of-south-africa-standards-andprocedures-system.html [Accessed: 22 November 2018]

Engineering Council of South Africa (ECSA). 2014. Qualification Standard for Bachelor of Science in Engineering (BSc(Eng))/Bachelor of Engineering (BEng). NQF Level 08. Document E-02-PE. $\quad$ Revision 4.41 July. https://www.ecsa.co.za/education/EducationDocs/E-02-PE.pdf [Accessed: 20 April 2018]

Engineering Council of South Africa (ECSA). 2017. Code of Conduct. Engineering Professions Act No 46 of 2000. Government Gazette. 142(40691). 17 March. Government notice 41. Cape Town: Government Printer. https://www.ecsa.co.za/regulation/RegulationDocs/Code_of_Conduct.pdf [Accessed: 20 April 2018]

Gimenez, J. \& Thomas, P. 2015. A framework for usable pedagogy: Case studies towards accessibility, criticality and visibility, in Lillis, T., Harrington, K., Lea, L. \& Mitchell, S. (Eds.). 2015. Working with Academic Literacies: Case studies towards transformative practice. USA: WAC Clearinghouse:.

Gwynne-Evans, A. \& English, J. 2014. Changes in teaching professional skills, including ethics, within an engineering faculty's skills development unit. South African Journal of Higher Education, 28 (1): 110-127.

Institute for Electrical Engineers (IEEE). 2012. Engineering. n.d. Engineering Professionalism. http://ewh.ieee.org/cmte/pa/Status/Professional.html [Accessed: 18 July 2017]

Jawitz, J., Case, J. \& Ahmed, N. 2005. Smile nicely, make the tea - but will I ever be taken seriously? Engineering students' experiences of vacation work. International Journal of Engineering Education, 21 (1): 134-138.

Krathwohl, D. 2002. A revision of Bloom's Taxonomy, Theory into Practice, 41 (4): 212-218.

Lauder, H., Young, M., Daniel, H., Balarin, M. \& Lowe, J. 2012. Educating for the knowledge economy?: Critical perspectives. Routledge: London.

Lillis, T., Harrington, K., Lea, L. \& Mitchell, S. (Eds.). 2015. Working with Academic Literacies: Case studies towards transformative practice. USA: WAC Clearinghouse. 
Martin, R., Maytham, B., Case, J. \& Fraser, D. 2005. Engineering graduates' perceptions of how well they were prepared for work in industry. European Journal of Engineering Education, 30 (2): 167-180.

Meyer, J. H. F. \& Land, R. 2005. Threshold concepts and troublesome knowledge (2): Epistemological considerations and a conceptual framework for teaching and learning, Higher Education 49 Spring: 373-388.

Nudelman, G. 2015. Reconceptualising employability skills: Constraints and enablements to discursive identity development in electrical engineering students in Proceedings of the 3rd Biennial Conference of the South African Society for Engineering. Education School of Engineering, University of KwaZulu-Natal, Durban 4-5 June 2015.

Rose, G. 1997. Situating knowledges: Positionality, reflexivities and other tactics, Progress in Human Geography, 21 (3): 305-320.

Sayer, A. 2011. Why things matter to people. Cambridge: Cambridge University Press.

Sfard, A. 1998 On two metaphors for learning and the dangers of choosing just one. Educational Researcher, 27 (2): 4-13.

Trowler, V. \& Trowler, P. 2010. Student engagement evidence summary. York, UK: Higher Education Academy.

Van der Vorst, R. 1998. Engineering, Ethics and Professionalism. European Journal of Engineering Education, 23 (2): 171-179

Wimpenny, K. \& Savin-Baden, M. 2013. Alienation, agency and authenticity: a synthesis of the literature on student engagement. Teaching in Higher Education, 18 (3): 311-326. 311326, http://dx.doi.org/10.1080/13562517.2012.725223.

Winberg, C. 2018. Book review. Book critiqued is Walker, M. \& Wilson-Strydom, M. (eds.). 2017. Socially just pedagogies, capabilities and quality in higher education: Global perspectives. London: Palgrave. Critical Studies in Teaching and Learning, 6(1): 8183.

Wolmerans, N., Smit, R., Collier-Reed, B. \& Leather, H. 2010. Addressing concerns with the NSC: An analysis of first-year student performance in Mathematics and Physics. Paper presented at the 18th Conference of the Southern African Association for Research in Mathematics, Science and Technology Education, Kwazulu-Natal: 274-284.

Woollacott, L.C. 2009. Validating the CDIO syllabus for engineering education using the taxonomy of engineering competencies. European Journal of Engineering Education, 34 (6): 545-559.

Young, M. 2012. Education, Globalisation and the voice of knowledge, in Lauder, H., Young, M., Daniel, H., Balarin, M. \& Lowe, J. (Eds.). Educating for the Knowledge Economy?: Critical perspectives. Routledge: London. 